\title{
UN CARACAZGO ANDINO Y LA SOCIEDAD CAMPESINA DEL SIGLO XVII
}

La historia de Bartolomé Tupa Hallicalla, curaca de Asillo.

Luis Miguel Glave

NO TRATAREMOS aca de un personaje común. Las evidencias de su actuación y sus propios testimonios, nos lo muestran como alguien cuya vida significaba mucho para las vidas de muchos, que estaban en contacto con él o que no lo estaban. Su práctica social y política lo puso en las más trascendentes situaciones del Perú de mediados del siglo XVII. Justamente, veamos de más cerca su vida y sus circunstancias para comprender la sociedad campesina, el concreto local de relaciones y el sistema colonial en el que él jugaba un papel de encrucijada. Entenderemos así, tal vez mejor, la vida de mucha gente común, de los campesinos y su organización en el siglo XVII.

Ubicación genealógica y simbólica del personaje

Bartolomé Tupa Hallicalla nació a fines del siglo XVI, creció con el siglo XVII. Probablemente vio la luz en el mismo pueblo de Asillo o en algún lugar de la provin- 
cia de Azángaro. Su familia nos es desconocida. Hasta donde sabemos, su padre pudo ser don Cristóbal Paucar Alli, quien ejerció el curacazgo de Asillo entre 1615 y 1647 (ver cuadro 1). Bartolomé afirmaba que su dignidad de señor del pueblo le venía por línea recta de varón, al uso de la ideología hispana aceptada en esa época. Su estirpe ejercía el cargo, de acuerdo siempre con su testimonio, desde el tiempo de los "ingas". Desde niño, fue preparado para ejercer el cargo, en la forma andina del adiestramiento, al punto que en 1674, cuando declaraba tener 75 años, afirmó sin dudar que tenía 70 de esos años como cacique (1).

Bartolomé Tupa Hallicalla debió tener algún grado de parentesco con el linaje de los Clemente Tupa. Su sucesor, a la sazón un anciano de 80 años, Ambrosio Clemente Tupa, era originario de la parroquia de San Blas en el Cusco. Los Clemente Tupa eran de la parcialidad urinsaya de la parroquia, del ayllu ingaconas, miembros de ese grupo inexplorado todavía de ingas del Cusco (2). Luis Clemente Tupa, un hermano de Ambrosio, se declaraba desde 1665 como descendiente de Pachacuti Inga y usaba como símbolo de su dignidad, la mascapaicha de los ingas, adjudicada por la junta de los 24 ingas de las ocho parroquias de la ciudad imperial (3).

Bartolomé contrajo un primer matrimonio justamente con una noble, miembro de uno de los ayllus de San Blas. Casó con Juana Guachuri, hija del Gobernador Juan Guachuri y Juana de Esquivel Yupanqui que a su vez era una de las hijas de Melchor Carlos Inca. El vínculo con San Blas, debía venir entonces desde tiempo atrás (4).

En general, la jerarquía de la sociedad nativa en el altiplano estaba compuesta mayoritariamente por familias trasladadas desde el Cusco. La jerarquía local había perecido a la llegada de los españoles y en la conquista (5). En reemplazo fueron trasladados los ingas del Cusco. 
Ese debió ser el caso de los nobles cusqueños, emparentados a las panacas incas o alguno de los linajes nobles que se prolongaron en la colonia, como los ayllus de San Blas (6). Por eso Bartolomé afirmaba que su ascendencia estaba atada a la jerarquía desde el tiempo del inga. Cuando no había ese parentesco, el mismo se buscaba por alianza.

El caso de los Manco Turpo de Azángaro está bastante documentado (7). Con ellos los Tupa y Halli en Asillo tenían estrechas relaciones. Lorenzo Manco Turpo, cacique gobernador de Urinsaya de Azángaro, en 1690 nos dejó la historia de su ascendencia. Lorenzo era hijo de Cristóbal Manco Turpo y Mensia Parpa Calsina, familia con la que Bartolomé Tupa Halli Calla tuvo estrechos contactos (8), nieto de Domingo Manco y bisnieto de Alonso Manco Husto. Domingo y Alonso estuvieron casados con dos mujeres de apellido Mollarme, Isabel y María Magdalena. Alonso Manco Husco y su mujer, de acuerdo con la tradición familiar, confirmada por los ancianos más respetables de la región, fueron trasladados a Azángaro, "por ser ingas", durante "la conquista destos reynos". Nuevamente, un origen cusqueño en familia atada a las jerarquías de un pueblo.

El personaje del que tratamos estaba atado a esta red de relaciones de los linajes cusqueños. Eso era determinante en la consecución de mecanismos de poder asentados en la creciente importancia simbólica del Inca durante el siglo XVII. Eso redundará en su posterior práctica y en su poder.

El curacazgo de Asillo

Nuevamente, las referencias que tenemos directas son relativamente tardías. La reflexión previa nos permi- 
te, sin embargo, un marco de referencias que la completa. El primer dato que tenemos es que el curaca de Asillo pertenecía a la parcialidad Anansaya en 1594. Pero luego, todos los curacas del pueblo durante el siglo XVII fueron de Urinsaya, incluso Ambrosio Clemente Tupa, nacido en San Blas pero incorporado en los linajes locales de Urinsaya a los que también perteneció Bartolomé Tupa Hallicalla. Los hombres que precedieron a Paucar Alli y Tupa Halli fueron miembros de la familia de los Copa Condori. Fueron ellos, desde 1594, los que fundaron una estancia administrada por los curacas y perteneciente al pueblo. Cuatro millares de ovejas de Castilla, que luego, como vimos, serían el negocio fundamental de la región, compartían pastos con algunos centenares de "carneros de la tierra', cargadores o llamas y “ovejas de la tierra”. El ganado recibió el cuidado de pastores proveídos por el propio virrey del Perú. Esa diligencia, que permitió la formación de una empresa centralizada en la jerarquía de los naturales, fue llevada adelante por los Copa Condori (9).

Luego, la estancia pasó al control de los Hallicalla. En términos globales, ese fue otro mecanismo de conjunción, apoyo y reproducción del grupo, administrado por la cabeza jerárquica del mismo. Parte de los negocios particulares del curaca, pero también una forma de apoyo de las acciones o praxis de éste en la reproducción del grupo.

En Asillo, entonces, el curacazgo fue ejercido dentro de pautas andinas y mestizas de sucesión. No encontramos ahí la presencia de advenedizos puestos por el poder externo del corregidor. Incluso, luego de la deposición de Bartolomé Tupa Hallicalla, por un conflicto en el que fue derrotado política y económicamente, se puso en el puesto a un "advenedizo" que, sin embargo, perteneció a grupos emparentados con la nobleza local, no exentos de conflictos. Conflictos que luego se manifestaron cuando 
el derrotado grupo que apoyaba a la "facción" de Bartolomé, se oponía al ejercicio del cargo por Marcos Javier Copa Condori, un nuevo miembro de la vieja dinastía de curaca en Asillo (ver cuadro 9).

Esa característica nos da una imagen de la influencia política que tuvieron los curacas de Asillo, particularmente Hallicalla. A la sabida importancia de sus funciones como enterador de tributos, "capitán de la mita" y pieza central en el tejido de las relaciones entre los naturales y el Estado como entre ellos y el mercado (10), una imagen de "señor" dentro de una sociedad impregnada de relaciones de dependencia personal, hacían del curaca de Asillo un actor social de primer orden, a través del cual conoceremos la sociedad rural altiplánica.

\section{La encomienda}

Hemos mencionado ya que los encomenderos del altiplano fueron de la más poderosa aristocracia cusqueña. En Asillo, la familia que fundó en Cusco Gerónimo de Costilla, fue la propietaria de la encomienda del pueblo. Pero no sólo se trató, en este caso, de una relación externa; el encomendero vinculó una gran estancia por vía de un patronazgo que lo hacía presente internamente, en una delicada red de relaciones de dependencia personal.

El encomendero de Asillo, Gerónimo de Costilla Gallinato, fundó en 1570 una obra pía en beneficio de sus indios. Se trató de una obra que partía de 230 ovejas de Castilla como base para la multiplicación. La obra o estancia de ganado debía cuidarse hasta llegar a las 10,000 cabezas de madres a partir de donde, los "multiplicos", irían en favor de los tributarios del pueblo como ayuda a sus tasas. Costilla estableció un vínculo perfecto de patronazgo en donde no debian intervenir las autori- 
dades públicas sino sólo los naturales y el patrón o sus sucesores. Costilla costeaba un administrador que vigilaba la buena marcha de la estancia que era visitada con cierta frecuencia por el patrón (11).

En 1607, el patrón del vínculo era Pedro Costilla de Noceda y éste "acudía" a los indios con cantidades que variaban desde los 250 pesos hasta los 400. Además, "algún" ganado se repartía como don a los "indios pobres". Con los curacas principales, la obra contribuía con 100 carneros para ayudar al sustento y decoro de las autoridades nativas y para las fiestas del pueblo. Además, se velaba por los enfermos costeando compra de medicinas y pago de un cirujano.

Los dones del vínculo incluían, por lo menos formalmente, el pago de salario a los miches (pastores) "como si no fuera ganado de su comunidad" (12). Esto es muy sintomático. Llevando el análisis de las relaciones sociales de los actores en la localidad a las relaciones de trabajo, descubrimos que la estancia vinculada, por el carácter del vínculo, estaba dotada de trabajo de los hombres del pueblo. Era, también, como la estancia que vinculó el curacazgo, un bien de comunidad. No lo era realmente, al punto que el vínculo establecía que las autoridades públicas no podían intervenir y justamente, los bienes de comunidad estaban adscritos al control de los corregidores o administradores establecidos por las autoridades coloniales. Sin embargo, en función del intercambio de pleitesías y dones con el patrón-señor, los campesinos eran llevados al trabajo. Para evitar sanciones de parte de la visita que Juan de Ciancas hizo en el distrito de la Audiencia de la Plata para la averiguación del cumplimiento de las leyes del servicio personal, se declaró que, como parte del bondadoso comportamiento del patrón, se pagaban a los miches de lo que presentaron como estancia de comunidad. 
El Estado concedió también una provisión forzada de trabajadores para el encomendero. Desde la época de Toledo, los Costilla tenían una cédula que los beneficiaba con 40 indios pastores, de los cuales 30 eran de Asillo. En 1607, Quimzacalco, estancia del vínculo, declarada como bien de la comunidad, tenía 11 mitayos que, como parte de los mecanismos de reciprocidad andina, eran ayudados para sus tasas y otros efectos, por el conjunto de los habitantes de la aldea. Pero, además de esta estancia, el encomendero Pedro de Costilla tenía dos estancias de ovejas con cerca de 10,000 cabezas, la más importante de las cuales era Purina. En las estancias del encomendero, incluidas dos de ganado vacuno, trabajaban 18 mitayos, con los que se completan los 30 campesinos de Asillo que se establecieron formalmente en 1570 (13).

Para los campesinos de Asillo, el trabajo en Omasbamba, nombre de la estancia que fundó Copa Condori, en Quimzacalco y Purina, era cotidiano y parte de su propio sistema rural en donde la reciprocidad y el dominio de señores, sean el curaca y sus familiares o sean los encomenderos o allegados, eran parte de su identidad y reproducción como grupo. Desde ahí resistían y enfrentaban la presión externa.

La tercera forma de organización del trabajo y concentración de bienes fue el de las cofradías. La iglesia estaba dotada de tierras con dos cofradías fundadas y dotadas con un número considerable de animales de matanza y lana. Esas cofradías fueron también una forma de recreación interna de vínculos (14) y fuente de recursos para enfrentar presiones externas y para el intercambio con el mercado mestizo regional. El patrón era fundamental para ello. En 1635, aparentemente, estaban también en la esfera del control del encomendero Costilla (15).

Las relaciones entre Bartolomé Tupa Hallicalla y Pedro Costilla eran excelentes, se necesitaban mutuamente 
como los dos señores administradores de los vínculos personales de dependencia de los campesinos. Políticamente se ayudaron también.

En esas condiciones, la conjunción de estancias de comunidad, del vínculo de patronazgo y cofradiales era casi un hecho. A mediados del siglo XVII, esa unión se produjo en manos del señor natural de Asillo, don Bartolomé Tupa Hallicalla.

Consolidación del poder curacal y defensa de las tierras indígenas

En 1646, el visitador de tierras en el Collao, Francisco Antonio de la Mazuela, compuso una estancia de ganado con un español avecindado en Asillo llamado Agustín Garrido. Todavía era curaca del pueblo don Cristóbal Paucar Halli que había recibido, luego de pormenorizada información, unas 28 estancias con media legua de circuito, para el común del pueblo. Garrido había "entrado" en una rica estancia desde 1644 y en el contexto de esa visita de composición de 1646, legalizaba su posesión de hecho. Debía pagar unos 140 pesos y finalizaba una diligencia, como muchísimas otras en esa época, de desposesión de tierras de naturales.

En 1648, no bien se hizo cargo del oficio de cacique gobernador del pueblo, Hallicalla planteó un recurso frente a la composición que había logrado Garrido.

Garrido no era un advenedizo interesado en hacerse de una estancia. En 1645, cuando el cura del pueblo, Lorenzo Ordoñez de Villaquirán quiso tomar como mayordomo las cofradías del pueblo, lo hizo acompañado de ese mismo Agustín Garrido, uno de esos "españoles entre indios" de los que hemos hablado (16). Ocupaba también el puesto de teniente del corregidor. En capítulo 
anterior hemos visto la importancia que tenían personajes como Garrido en las mediaciones de poder que se requerían para conseguir recursos mercantilizables. Contra alguien así, que quería además posesionarse de bienes en tierras del pueblo, se alzó la primera maniobra legal de Tupa Hallicalla.

Con recurso ganado ante la Real Audiencia, como muchas de las acciones legales que realizó Tupa Hallicalla, gastando gran cantidad de dinero, el pueblo de Asillo se opuso a la composición de Payamarca. El corregidor hizo una información para confirmar si se trataba de tierras del pueblo que tenía entonces el derecho de ser preferido en composición por el tanto de lo ofrecido por cualquier postor. Garrido las había compuesto como tierras de Orurillo, pueblo que no se opuso a la entrada del español. Desde mucho tiempo atrás, se había llevado adelante una contienda de linderos -en el mismo esquema que desarrollamos ya en este capítulo- entre Asillo y Orurillo por las tierras de Payamarca (17). Había que demostrar que las tierras eran de Asillo para el buen éxito de la gestión hecha ante la Real Audiencia. Se hizo declarar a los curacas de Orurillo, particularmente a Don Carlos Chaguasongo. Dijeron que las tierras eran de Asillo, a pesar del largo tiempo en que habían llevado pleito y los habían prácticamente ganado. ¿Por qué lo hicieron? El alegato de Garrido nos da la respuesta. Bartolomé Tupa Hallicalla ofreció a Carlos Chaguasongo -también Achaguasongo4,000 pesos para ayuda de tasas y le dio en efectivo otros 500 para que afirmara que las tierras eran de Asillo. Bloqueada la pretensión de Garrido, la estancia volvería a Orurillo. Cuando el escribano Andrés de Covarrubias declaró, afirmó haber escuchado él mismo a Bartolomé hablando con los jefes de Orurillo con quienes dijo no tener pleito y que una vez derrotado Garrido, la estancia 
volvería a ser de Orurillo y todos "estarían con toda paz y quietud como lo avían estado antes".

El testimonio dado por los testigos de parte de Garrido podría ser interesado, pero en algo basdo en evidencias. Para ellos, Tupa Hallicalla quería perjudicar a los españoles. Evidencias posteriores demuestran que el curaca hizo muchas acciones de este tipo, en pos de evitar la presencia, dentro del ámbito de influencia de sus intereses, de competidores con carácter "externo" a su grupo de poder dentro del mundo campesino andino.

Las maniobras por el control de Payamarca no terminaron ahí. En 1653, el visitador de tierras de la "Junta de desagravio de los indios', Fray Pedro Velasco, retomó todas las composiciones hechas en el contexto de la irregular visita de Mazuela. Con el caso de Payamarca hizo las averiguaciones pertinentes, descubriendo que las tierras eran de la jurisdicción de Orurillo. Por ello, rectos como fueron esos visitadores de "desagravio", ofreció la estancia a los de Orurillo que no la pidieron al haber sido restituidos en seis ricas estancias y saber, seguro, que Bartolomé Tupa Hallicalla tenía el deseo de continuar en la posesión. Por eso se puso la estancia en remate. La obtuvo Tomás Bereo por 3,000 pesos. La suma fue absolutamente alta respecto a los menos de 150 pesos con que se habían rematado en 1646 , fue una postura insuperable. Bereo era un "blanco pobre" residente en Asillo, sin posibilidad alguna de adquirir una estancia y menos pagar 3,000 pesos (18). Se trató de otra maniobra por la que el curaca Tupa Hallicalla logró conservar la estancia, acrecentando así su dominio como el gran señor de la zona: juntaba su mayordomía de cofradías al economato de la iglesia, el control de la obra del encomendero, la estancia de comunidad y Payamarca. 
La actividad política curacal: la mita

Entre los cargos que debían cumplir los señores naturales, el de capitán de la mita era uno de los más importantes. Tupa Hallicalla había sido ya varias veces capitán de Asillo. Conocía bien sus mecanismos y, como muchos señores naturales, usaba el cargo como una manifestación más de su señorío y preeminencia. Además, hacía buena combinación de su viaje como agente de la mita con actividades ante la corte de la Real Audiencia y negocios de chacaneo, de vino, coca y ají.

Cuando curaca, desarrolló lo que había ido aprendiendo con el tiempo. Vigilaba sus negocios con la villa de Potosí, viajaba constantemente para "capitular" con autoridades, pedir la salida de españoles de los pueblos, controlar los indios que tenía "fugados", "reducirlos" cuando era de su interés. Pero lo que más importancia tuvo para el conjunto de la sociedad andina fue su participación en la campaña legal contra la mita. En 1657 hizo la presentación de la provisión del Conde de Alva contra la mita de faltriquera y participó activamente en las campañas o "pleitos con los azogueros" como decía el curaca (19). En 1668, obtuvo un valioso apoyo del propio Conde de Lemos, usando sus cargos y méritos frente al virrey que fue al altiplano en medio de una gran tensión política, como analizamos oportunamente.

Lo que el curaca consiguió de las más altas esferas del poder, en un universo fuertemente marcado por el afán de prestigio, que consolidaba los vínculos de dependencia personal, no fue poco. Mucho más llamativo es, además, que haya logrado esas dignificaciones, siendo un activo querellador contra la mita y contra los blancos en el altiplano. El Conde de Santisteban le confirió el título de Capitán de Infantería de los naturales de Asillo, en 1661 luego que el curaca protegiera a los españoles de 
la plaza que combatieron por el virrey durante las alteraciones de Laycacota y La Paz. Tupa Hallicalla dio para el efecto, además de dinero efectivo: 1,600 carneros de la tierra que él empleaba en sus gruesos trajines, harina, vino, ají y otros efectos que él comerciaba entre la costa, el Altiplano y Potosí. Finalmente, como tenía en Asillo gente de paso para los enfrentamientos, puso a disposición de los combatientes "todo el ganado de Castilla y bacuno que tiene en sus estancias" (20).

Luego, cuando pasó el Conde de Lemos a develar el alzamiento de los Salcedo, en 1667, en mérito a su apoyo, nombró a Bartolomé Tupa Hallicalla Maestre de Campo de las ocho parroquias de Cusco. Convalidando de esa manera el prestigio nativo del curaca que vivía en Cusco parte del año (21), tenía como la nobleza cusqueña en general, una finca en Urubamba y había casado en segundas nupcias con Doña María Simbrón de Mendoza (22), mujer “española" de la sociedad cusqueña que tenía vínculos familiares con grupos de la nobleza nativa.

Con esas prerrogativas concedidas, que le permitían montar a caballo, usar daga y espada, gozar del fuero militar y sólo poder ser encausado por el gobierno, el curaca todavía hizo relación de sus méritos al Consejo de Indias de 1673, pidiendo se le confirme en algún oficio o se le dé una encomienda de indios (23). Como se ve, la mentalidad del hombre estaba llena de imágenes coloniales y señoriales y aspiraba, siendo dignidad de la "república de indios", a llegar a la esfera del poder de la "república de españoles". En Madrid, la Reina Gobernadora emitió una Cédula en 1673 por la que recomendaba al curaca para ocupar oficios y cargos correspondientes a sus servicios distinguidos (24).

En ese mismo momento, Bartolomé viajaba a La Plata a continuar con sus "pleitos con los azogueros", elevando papeles a la metrópoli, haciendo informaciones, coordi- 
nando con otros curacas una campaña contra la mita que pasaba por un momento de agitación central en el siglo como se ha visto. También, ese año de 1673, luego de haber amenazado al corregidor anterior con denunciarlo por los abusos que siempre cometían en sus tratos esos funcionarios, estuvo más bien apoyando a Francisco Castro, corregidor entonces de Asillo, ante un juicio por capítulos que le pusieron algunos ayllu curacas $\mathrm{y}$ caciques de la parcialidad Anansaya (25). Las actuaciones legales del curaca eran parte de maniobras muy bien dirigidas de acuerdo a metas de poder personal pero también, de afirmación política del partido de curacas que él integraba.

Un testimonio de 1673, nos revela la magnitud de las actividades del partido de los curacas. El mismo personaje que buscaba ser reconocido por el poder español, que sirvió al bando aliado a Lima en las alteraciones de la década de 1660, había extendido su acción judicial a la abierta conjuración. El testimonio dice que:

"Estando este testigo en el pueblo de Puno en ocación que estubo en el Exmo. Señor Conde de Lemos Virrey que fue destos reynos donde se hallo tambien Don Diego Layme Sucapuca cacique del pueblo de Taraco... le dixo a este testigo como le avia comunicado y propuesto el dicho Don Bartolome antes que su excelencia ubiera benido al pueblo de Puno en ocassion que en Lima trataron de Alzarze algunos caciques en aquella ciudad como le avian embiado a que se conbocasen con ellos para el dicho alsamiento y que asi por esta caussa le inssito al dicho don Diego Suca Puca el susodicho dissiendo que era buena ocacion la presente para que el biniera a la combocacion dicha y aunarse con el para con los otros deLima..." (26). 
Revelador testimonio que por las fechas, los datos colaterales y el contexto que analizamos en capítulo anterior, parece de toda validez. Otros testimonios confirmarán la existencia de contactos, cartas y organización de esa convocación de los curacas. Incluso, alguno recordó que en una de sus estancias, el curaca reunió a los campesinos y principales en junta donde advirtió se debían preparar para acudir al alzamiento. Todos remarcaban el gran respeto y obediencia que el curaca tenía de sus naturales, los que lo trataban como su Rey y señor; sobre todo el testigo que denunció la asamblea de la estancia, un escribano del pueblo, sobrino del curaca, hombre de 60 años en 1673. En 1666, año de la abortada rebelión de Lima, Bartolomé Tupa Hallicalla estuvo en Cusco sintomáticamente y seguía representando a muchos de sus allegados curacas como que tenía entonces el albaceazgo de los bienes que fueron de Pedro Calsina, gobernador de Azángaro (27).

No fue denunciado por nadie entonces. Los testimonios salieron a luz años después, en otro contexto, desfavorable para quien fue poderoso señor de naturales. Todavía continuó obteniendo concesiones del poder central en su rango $\mathrm{y}$ autoridad $\mathrm{y}$ denunciando judicialmente los abusos de la mita, incrementando sus bienes y su empresa curacal.

Los bienes y la empresa del curaca

En 1651 se llevó a cabo la sustanciación de una causa criminal contra Cristóbal Vargas Carbajal, cura de Azángaro, puesta por los curacas del pueblo (28). Los jefes de Azángaro se pusieron de acuerdo para "entablar" al cura por una serie de abusos. El curaca Calsina, de la facción y amigos de Tupa Hallicalla, encabezó la acusación. Entre 
los testigos, uno conspicuo: Bartolomé Tupa Hallicalla. Debemos traer a colación este enfrentamiento por tres motivos. Uno es que se trata de otro de los tantos pleitos que patrocinó, apoyó y llevó adelante el curaca de Asillo en su táctica legal, en la que empleó ingentes recursos monetarios y puso en movimiento una sutil red de relaciones locales que alguna vez se calificó como: "las provincias de lampa carabaya azangaro que a todo esto se estiende la mano y cabilasion de cicho cazique" (29). Otro tiene que ver con el enfrentamiento a un doctrinero, actor de ese concreto local de relaciones del que hablamos que, en años adelante, entraría, en el contexto de la acción política del obispo Mollinedo, en una ofensiva abierta contra los señores naturales y sus mecanismos de poder. El tercero está relacionado con la acusación central al cura Vargas Carbajal, el uso de recursos nativos para empresas mineras en el Altiplano.

El conflicto político más importante del siglo explotó en función de los intereses desatados en torno a las fabulosas minas de Laycacota. Ahí se engendraron las fortunas más grandes del siglo. En toda la zona, existen indicios de una gran actividad minera fuera del control estatal y sin provisión de mitayos. No sólo Laycacota, también San Antonio de Esquilache, Vila Vila èn Lampa y minas por todo el territorio, hasta las alturas de Canas en el cerro de Condoroma.

El cura de Azángaro en 1650 había mantenido un sistema local de relaciones para la marcha de la explotación minera en San Antonio de Esquilache. Vargas Carbajal apremiaba a los curacas a darle indios para enviarlos a las minas. Daba a los jefes naturales plata piña adelantada para pago de salarios de jornaleros que eran "sacados" con el pretexto de llevarlos a San Antonio de Esquilache a labores urbanas como "hacer adobes". Como todos los que adquirían, por su posición en las relaciones colonia- 
les locales, algo de poder amparado en el uso de facultades públicas y usando un beneficio privado, el cura también lograba conciertos con los curacas para obtener trabajadores "a cuenta de tasas". Vargas Carbajal podía usar la presión del tributo en su provecho ya que su alianza con el corregidor Alonso de Madrid y Luna era evidente. Tanto lo era que cuando se hizo la residencia del corregidor, al cura se le acusó de ocultar en su casa 36,000 pesos en reales para que no los embargaran como rezagos causados durante su ejercicio. El cura llevaba campesinos como mineros incluso en los casos de aquellos que llegaban de cumplir con su mita en Potosí. Su negocio no sólo era el de usar fuerza de trabajo escasa en minas suyas sino también en la de mineros que tenían tratos con él, como Bartolomé García, Cristóbal Ponce de León o Alonso de Pineda.

Junto con el trabajo de mineros, los naturales debían trabajar en el transporte de Azángaro a San Antonio, llevando un insumo precioso a la labor de las minas: la sal. En las cercanías de Azángaro, los naturales gozaban en abundancia de ese recurso, que usaban en sus intercambios. Cuando creció el uso minero de la sal, el cura se fue apropiando del recurso de manera monopólica, usando sus relaciones con la empresa nueva que se creaba. Tenía, tomados también de las economías campesinas, unos 1,000 carneros destinados a ese trajín.

Las actividades mineras, el pago efectivo en "plata piña" y la concentración de gente, fueron un dinamizador de nuevos intercambios en esa época, desde mediados del siglo XVII. Desde Quispicanchis, los campesinos usados en los tratos del corregidor, llegaban a San Antonio llevando coca y harina en sus carneros, apropiados a cambio de tasas por el corregidor (30).

Las acusaciones contra el negocio del cura podrían pasar como un conflicto más de los muchos que nos ilu- 
minan las relaciones concretas de la vida de los campesinos, pero resultan también una evidencia particular. Bartolomé Tupa Hallicalla fue, también, uno de los más emprendedores mineros de la región. Tenía un trapiche en Surupana, cerca a su pueblo, varias minas en Pucara y llegó a juntar hasta 78 campesinos mineros en el cerro de Vila Vila. Cuando se autodenominaba con cargos y méritos, a sus títulos de Maestre de Campo y Gobernador añadía, al uso de aquéllos que resaltaban sus méritos en servicio de la Corona, el de dueño de minas y trapiche. Su actividad la llevó al campo de la exploración con cierto suceso al punto que cuando su situación era muy mala por el ataque de que fue objeto, todavía denunció el hallazgo de una buena veta cercana al Cusco (31).

Ya hablamos de sus trajines, en la posición inmejorable de control de ganado y trabajo de sus sujetos. Otros curacas que desarrollaron los trajines han sido ya felizmente estudiados (32). Tupa Hallicalla no difería de ese modelo. Su éxito en esa forma mercantil está fuera de duda, pero no parece haber sido el rubro principal de sus actividades. Fueron las minas su principal interés, siendo ese sector el más importante del sistema. Pero lo que llena la documentación es el control de las estancias. Como hemos visto se hizo señor absoluto de la tierra y el ganado. Tenía en su pueblo establecido un señorio en donde los competidores eran eliminados de cualquier forma, como ocurrió con Garrido. En 1675 se registraron en "sus" estancias por lo menos 22,000 cabezas de ganado. El señorío ganadero, uno de los más importantes de que tengamos noticia, no era la única actividad agropecuaria que controlaba. Al lado de la servidumbre y sumisión de sus sujetos y "forasteros" que recibía con mano de "señor natural", establecía otras formas de relación con los hombres de su pueblo. Mandaba hacer chacras, fuera de las que se hacía en terrenos de las estancias, a los campesinos en 
una reproducción de las chacras colectivas que le permitían relaciones de contradones y reciprocidad bondadosa del señor. La diferencia entre su empresa y la de los corregidores, ajenos a la localidad, o la de cualquier hacendadocomerciante-corregidor de la república de españoles, fue ese control de la reciprocidad andina y el reconocimiento a su señorío natural; poder que, como hemos visto, se granjeó y usó también en la defensa de una personalidad andina totalmente incorporada en un conjunto en plena efervescencia de mutaciones.

Conflicto con el poder político de los curas y derrota curacal

Entre 1675 y 1678, todo el poder y los recursos del curaca de Asillo no pudieron evitar que fuera derrotado por la acción del cura del pueblo, Don Antonio García Salas y Valdés, apoyado abiertamente por el obispo del Cusco Manuel de Mollinedo y su sobrino Andrés, visitador eclesiástico del Altiplano. Fueron embargadas sus estancias; las minas sin cuidado y sin trabajadores se arruinaron; los grupos de jefes nativos enfrentados con su linaje y recelosos de su poder lo reemplazaron en la jefatura; se le pusieron causas por "abusos", estuvo fugitivo casi tres años y preso uno. Apeló tres y cuatro veces, a Cusco, al Tribunal Eclesiástico Metropolitano de Lima, a la Real Audiencia de La Plata y finalmente ante el Consejo de Indias. Preso en La Plata obtuvo orden de desembargo de bienes y el propio virrey se interesó en su caso y pidió se tuviera consideración a su persona y se le hiciera justicia. Ni Valdez ni Mollinedo obedecieron y las causas siguieron su trámite. Viejo y derrotado murió en La Plata al poco tiempo. 
Las estancias fueron apropiadas por el cura del pueblo y vendidas en pública subasta (33), luego el obispo Mollinedo ordenó vender estancias de las cofradías para sólo usar el "principal" y librarse del manejo de las estancias. Los clérigos, como García Salas y Valdes lograron apropiarse de bienes de jefes naturales y del común, un estudio de sus acumulaciones personales arrojaría resultados sorprendentes. El Obispo estuvo detrás del cura y fue la voluntad política que derrotó la fuerza social regional del curaca. El tema escapa ahora a nuestro trabajo, basta señalar su importancia para explicar el engranaje contra el que chocó la sociedad nativa hegemonizada por curacas como Tupa Hallicalla.

En 1678, cuando ya habían obtenido una crden de desembargo de sus bienes que no se cumplió nunca, María Simbrón de Mendoza escribió una carta desde Azángaro a Bartolomé Tupa Hallicalla, su marido preso o retenido en La Plata (34). Agradecida por las gestiones de su marido, que logró que ella conservara la casa en Cusco, no deja de señalar la miseria a la que habían sido conducidos por lo que resultaba una clara alianza entre el cura García y el nuevo corregidor Iñigo Torres de Zúñiga. La esposa avisaba a Tupa Hallicalla que el conde de Portillo, sin embargo de haber sido instrumento del cura en el embargo de los bienes por la causa que inició ante el Dean del Cusco por cuentas de las cofradías (35), se ofrecía ahora como mediador y apoyo para el curaca o Mallku de Chucuito, don Bartolomé Cari "muy descuidado" por su edad y no se podía dejar acciones importantes en sus manos. En cambio, un curaca de Ayavire, don Gerónimo, había sido encarcelado y acusado de diversos delitos, le pedía a Bartolomé que viera por él ante el Presidente y Oidores de esa Audiencia.

Cartas cruzadas entre jefes étnicos, intercambios de gestiones, cambios de actitudes, son elementos que apare- 
cen en esta carta que nos muestra a un hombre que a pesar de su derrota seguía activo en un mundo en donde todavía significaba un liderazgo. Sin embargo, su sistema se estaba derrumbando, acabando como su vida en el destierro. Dejemos a la propia María Simbrón retratar la situación:

"El trapiche y las obejas lo an embarasado por desir ques de D. Pablo (Costilla) porque el tal don Pablo a alcansado una probision desa audiencia para que te hisieran cargo como te han hecho de siento y ochenta mil pesos de marmullas y servicio de indios y de la plata que se juntaron disen para quitar las estancias que quitastes de los españoles, no se que berdad aiga para esto...' (36).

Fue acusado de recibir los servicios de la reciprocidad andina y por la jefatura étnica que le permitían usar trabajos como el de las "marmullas" o mujeres que hacían chicha "como en tiempo del inga", todo el sistema andino que el curaca usó en su provecho y en la reproducción de su sociedad y su hegemonía dentro del orden colonial. Orden al que se adaptó incluso en sus ideas y representaciones, como vimos, pero que enfrentó en sus agentes locales como esos "españoles" a los que impidió apropiarse de tierras. Todo eso que funcionó durante cincuenta años de su vida, de la historia del Perú, era entonces la acusación a un hombre, a uno solo. El sistema se derrumbaba, lentamente, dejando intactas sin embargo muchas cosas. Luego, las referencias sobre la vida de Bartolomé Tupa Hallicalla se fueron perdiendo en el tiempo. 


\section{Claves utilizadas}

Repositorios:

AAA Archivo Arzobispal del Cusco.

AAL Archivo Arzobispal de Lima.

AGI Archivo General de Indias, Sevilla.

ANB Archivo Nacional de Bolivia, Sucre.

AHC Archivo Histórico del Cusco.

AGN Archivo General de la Nación, Lima.

BN Biblioteca Nacional, Sala de Investigaciones, Lima.

Abreviaturas:

JR Juicios de Residencia.

EC Expedientes coloniales.

Ms Manuscrito.

Prot. Protocolo.

f Folio.

Leg Legajo.

C Cuaderno.

DI Derecho Indígena

J.O Justicia Ordinaria.

G García (sección). 


\section{Notas}

(1) ANB. EC. 1675.22.

(2) AHC. Testimonios-compulsas, Leg. 1.

(3) AGI. Lima 175.

(4) Revista de Archivo Histórico del Cusco No. 11; ANB, EC. 1675.22.

(5) Saignes 1985.

(6) BN, Ms. B. 561.

(7) AHC. Testimonio-compulsas, Leg. 1.

(8) AHC. Cabildo, J.O. Varios, Leg. 117, 1565-

1824.

(9) ANB. EC. 1607.14.

(10) La lista de trabajos en este sentido va creciendo,

nos remitimos acá al aporte inicial del análisis de SánchezAlbornoz (1978) y a los estudios hechos por Silvia Rivera (1978), Murra (1978) y Saignes y Loza (1984).

(11) AGN. DI. Leg. XI, Cuad. 160; AHC. Prot. Luis Diez de Morales 1635 y 1661 .

(12) ANB. EC. 1607.15.

(13) ANB. EC. 1607.12 y 1607.13 .

(14) La idea fue adelantada en el artículo de Fernando Fuenzalida (1970) que constituye ahora una guía para la reformulación de hipótesis y el uso de una abundante información historiográfica que hace casi dos décadas no se manejaba en absoluto. Trabajos posteriores han incidido felizmente ya en la importancia de las cofradías como generadoras de nuevos vínculos colectivos.

(15) AHC. Prot. Luis Diez de Morales 1635.

(16) AAL, Apelaciones Cusco, Leg. 23.

(17) BN. Ms. B. 1491.

(18) AAC. G. 9-212-1.

(19) AGI. Charcas 268, No. 61-A.

(20) AGI. Lima 171.

(21) AHC. Cabildo J.O. Leg. 117.

(22) ANB. EC. 1678. 21.

(23) AGI. Lima 171.

(24) ANB. EC. 1675. 22.

(25) ANB. Minas T. 125, No. 19.

(26) ANB. EC. 1675. 22.

(27) AHC. Cabildo, J.O. Leg. 117.

(28) AAL. Apelaciones, Cusco, Leg. 10.

(29) ANB. EC. 1675. 22.

(30) AGN. JR. Leg. 35, Cuad. 103. 
Un curacazgo andino del siglo XVII

(31) ANB. EC. 1675. 21 y 1675. 22.

(32) Ver sobre todo los trabajos de Roberto Choque Canqui (1978 y 1979).

(33) AAC. G. 9-212-1 y AGN.
DI. Leg. 12, Cuad. 209.

(34) ANB. EC. 1678.21.

(35) AAL. Apelaciones, Cusco, Leg. 23.

(36) ANB. EC. 1678.21. 


\section{Bibliografia}

ABERCROMBIE, Thomas:

1986 "Articulación doble y etnogénesis". (Ponencia presentada al Simposio sobre Reproducción y Transformación de las sociedades nativas en los Andes, SSRC, Quito).

ALENCAS'TRE, Andrés y Georges DUMEZIL:

1953 "Fétes et usages des indiens de Langui". En: Journal de la Societé des Americanistes T. XLII, pp. 1-118 (Paris).

BERTONIO, Ludovico:

(1612) 1984 Vocabulario de la Lengua Aymara. Ed. Facsimilar (Ceres, La Paz).

\section{CENTRO DE FORMACION CAMPESINA:}

1985

"Experiencias en empresa intercomunal". En: Promoción Campesina, Regionalismo y Movimientos Sociales (DESCO, Lima).

CIEZA DE LEON, Pedro:

(1533) 1984Crónica del Perú. (Pontificia Universidad Católica, Fondo Editorial, Lima). 
COOK, Noble D.:

1975

Tasa de la visita general de Francisco de Toledo. Edición y prólogo de ... (Universidad de San Marcos, Lima).

CUNEO VIDAL, Rómulo:

$\mathrm{s} / \mathrm{f}$

Historia de las guerras de los últimos incas peruanos contra el poder español (15351572). (Casa Maucci, Barcelona).

CHOQUE CANQUI, Roberto:

1978

"Pedro Chipana: cacique comerciante de Calamarca'. En: Avances No. 1, pp. 28-32. (La Paz).

1979

"Las haciendas de los caciques Guarache en el Alto Perú (1637-1734). En: América Indígena, Vol. XXXIX, No. 4 (México).

EARLS, John e Irene SILVERBLATT:

1979 “Ayllus y Etnias en la región Pampas-Qaracha. El impacto del Imperio Incaico'. En: Investigaciones. Ciencias Histórico Sociales Vol. II. No. 2, pp. 267-282 (Universidad San Cristóbal de Huamanga, Huamanga).

FUENZALIDA, Fernando:

1970 "Estructura de la comunidad indígena tradicional: una hipótesis de trabajo”. En: J. Matos Mar (ed.) Hacienda, comunidad y campesinado en el Perú, pp. 219-265 (Instituto de Estudios Peruanos, Lima). 
GALDOS, Guillermo

1984 "Cuando el Kollisuyo Incaico devino en Colesuyu colonial'. En: Revista del Archivo General de la Nación No. 7, pp. 177-184 (Lima).

1985

Kuntisuyu: lo que encontraron los españoles. (Fundación M.J. Bustamante, Arequipa).

GLAVE, Luis Miguel y María Isabel REMY:

1983

La racionalidad de la organización andina (Instituto de Estudios Peruanos, Lima).

HAMPE, Teodoro:

1979 "Relación de los encomenderos y repartimientos del Perú en 1561". En: Historia y cultura No. 12, pp. 1-43 (Lima).

HUERTAS, Lorenzo:

"Tributación indígena en Huamanga colonial'. En: Revista del Archivo General de la Nación No. 8, pp. 31-78. (Lima).

JIMENEZ DE LA ESPADA, Antonio:

1965 Relaciones geográficas de indias (Biblioteca de Autores Españoles, Madrid).

JULIEN, Catherine:

1983

Hatungolla: A View of Inca Rule from the Lake Titicaca Region (University of California, Press, California). 
LINARES, Germán:

1943

"Yanaoca: ensayo de una interpretación sociológica'. En: Túpac Amaru, Vol. II, No. 2-3, pp. 12-18 (Cusco).

MARKHAM, Clement:

1923

Las posesiones geográficas de las tribus que formaban el imperio de los incas (Col. de libros y documentos referentes a la historia del Perú, Lima).

MARTINEZ, Gabriel:

1984 "Espacio Lupaga: algunas hipótesis de trabajo'. En: Amalia Castelli (comp.) Etnohistoria y antropología andina. pp. 263-280 (Museo Nacional de Historia, Lima).

MAURTUA, Víctor:

1906

Juicio de límites entre Perú y Bolivia, T. I. (Barcelona).

MIRANDA ROCHA, Aurelio:

1967

"Las artesanías en la provincia de Canchis". En: Cuatro estudios, Canas y Canchis (Instituto Indigenista Peruano, Lima).

MURRA, John:

1975

Formaciones económicas y políticas del mundo andino (Instituto de Estudios Peruanos, Lima).

1978

"La correspondencia entre un "capitán de la mita y su apoderado en Potosí". En: Historia y Cultura No. 3, pp. 45-58 (La Paz). 
RIVERA, Silvia:

1978

"El Mallku y la sociedad colonial del siglo XVII'. En: Avances No. 1, pp. 7-27 (La Paz).

SAIGNES, Thierry:

1984

"Las etnias de Charcas frente al sistema colonial'. En: Jahrbuch Für Geschichte... Lateinamerikas No. 42, pp. 27-75 (Colonia).

1985 Caciques, Tribute and Migration in the Southern Andes (Institute of Latin American Studies, University of London).

1985-A Los andes orientales: historia de un olvido (Ceres, La Paz).

1985-B "Algún día todo se andará: los movimientos étnicos en Charcas (siglo XVII)". En: Revista Andina No. 6, pp. 425-450 (Cusco).

SAIGNES, Thierry y Carmen B. LOZA:

1984

"El pleito entre Bartolomé Qhari, Mallku de los Lupaga y los corregidores de Chucuito (1619-1643)"'. En: Historia y Cultura No. 5, pp. 29-49 (La Paz).

SANCHEZ ALBORNOZ, Nicolas:

$1978 \quad$ Indios y tributos en el Alto Perú (Instituto de Estudios Peruanos, Lima).

STERN, Steve

1982 Peru's Indian Peoples and the Challenge of Spanish Conquest. (The University of Wisconsin Press, Madison). 
VACA DE CASTRO, Antonio:

1543-1909 "Ordenanzas de Tambos: distancias de unos a otros, modo de cargar los indios y obligaciones de las justicias respectivas hechas en la ciudad del Cusco por...'. En: Revista Histórica T. III, pp. 427-492 (Lima).

VAZQUEZ DE ESPINOZA, Antonio:

1628-1969 Compendio y descripción de las indias occidentales. (Biblioteca de Autores Españoles, Madrid).

VILLANUEVA, Horacio

1982 Cuzco 1689. Documentos. (Centro Las Casas, Cusco). 